\title{
The ancient Roman gate along Appian way: San Sebastiano Gate
}

\author{
Michele Russo $^{\text {a }}$, Fabio Lanfranchi ${ }^{\text {b }}$, Laura Carnevali ${ }^{\mathrm{c}}$ \\ Dipartimento di Storia, Disegno e Restauro dell'Architettura, Sapienza Università di Roma, Rome, Italy \\ a m.russo@uniroma1.it; ${ }^{\mathrm{b}}$ fabio.lanfranchi@uniroma1.it; ${ }^{\mathrm{c}}$ laura.carnevali@uniroma1.it
}

\begin{abstract}
The application of integrated survey techniques and 3D modelling methodologies for Cultural Heritage analysis is now considered a consolidated process, while preserving and suggesting continuous research lines related from one side to the evolution of acquisition and restitution instruments, from the other to the problems linked to the specific case study and the goal of the research. This article describes the analysis of one of the largest and best-preserved gates of Rome, located within the Aurelian walls: Porta San Sebastiano. The original name of this gate was Porta Appia, transformed in the Middle Ages into San Sebastiano from the name of the Christian martyr buried in the Basilica on the Via Appia, located just outside the walls. The current gate aspect is the result of many architectural changes over the centuries, as well as a transformation happened in the twentieth century which has led it to a residential use, a unique example of its kind. Through the integration of different survey techniques, a geometric analysis of the complex building is completed, highlighting the construction complexity and the spatial articulation. A parametric model of a portion of the building is then suggested, aimed at understanding the logic underlying the definition of a HBIM model related to an existing complex artefact. Through an integrated analysis, the aim of the article is to provide an advancement in the knowledge of the specific Cultural Heritage through the integration of complementary methods of analysis and representation.
\end{abstract}

Keywords: Urban gate, integrated survey, morphological analysis, parametric modelling.

\section{Introduction}

The Roman walls framework built between 270 and $273 \mathrm{AD}$ by the emperor Lucius Domitius Aurelian, was structured through a closed section that defined, for most of its path, the commercial border of Rome and its customs offices, strategically placed from $175 \mathrm{AD}$ on the major consular roads leading to the city. (Tomassetti, 1975). So, at least ideally, before being a defensive system the main Roman city wall found its beginning in economic needs. (Brizzi, 1995). In this context, San Sebastiano Gate, built next to Druso Arch, a barrel-vault of the Antoninian aqueduct which will remain inextricably linked to the historical evolution of the gate itself (Stacci- oli, 1969), represents an emblematic example of the articulated transformations through 1750 years of history about the Roman walls and its access system (Fig. 3). An analysis about the state of the art and the gate transformations has been carried out using the survey in its widest meaning, that is both in terms of direct investigation conducted on site with the most recent methods of acquisition, and archival one, arriving at digital representations, data interpretation and first experimental results of BIM modelling, on which a critical analysis had been carried out. 


\section{Case study}

Porta San Sebastiano, also known as Porta Capena or Appia, is one of the main and bestpreserved gates of Rome (Fig. 1), located at the beginning of the Via Appia Antica south of Rome (Gallavotti Cavallero, 1989). The history of the gate covers almost 1750 years, starting from the date of its foundation between 271 and 279 AD under Aurelian's Emperor, author of one of the most important masonry works in the history of Rome (Giovenale, 1931; Mancini, 2001). The gate was initially built with two arches and two semi-circular towers, like other main gates of Rome at the beginning of the most important road axes. The monument, named previously Porta Capena in place of the homonymous ancient gate located at the inner Servian walls, in modern times is called Porta Appia or San Sebastiano, in memory of the martyrs buried in close catacombs (Cambedda, Ceccherelli, 1990).

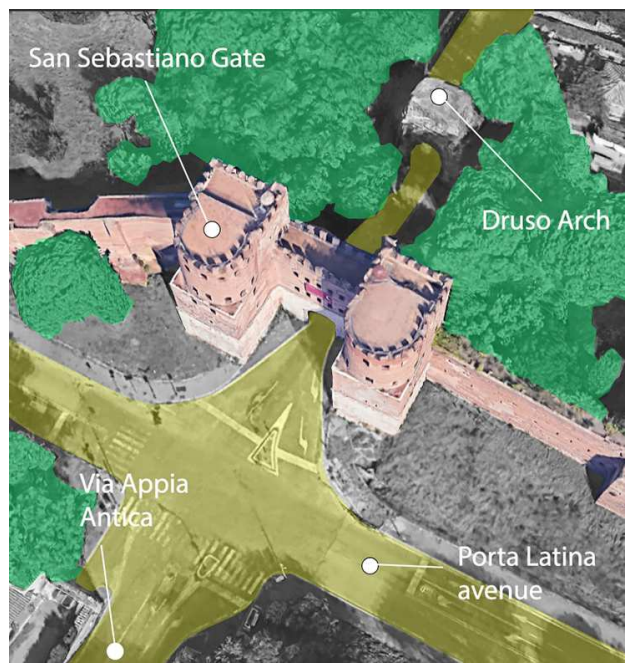

Fig. 1. Satellite view (source: Google Earth) of the urban setting of San Sebastiano gate, highlighting the roadways (yellow) and the tall trees (green).

The history of the building can ideally be divided into seven time periods (Fig. 3), marked by relative external and internal transformations (Richmond, Jacobsen, 2013; D'Ippolito, 2017). The first three phases regard the first two hundred years of the gate and concern the main structural changes.
In such sense must be highlighted the transformation of the towers (Fig. 2), the closing of a barrel-vault, the construction of a counter gate, the inclusion of quadrangular ramparts to stiffen the building after seismic events, which have significantly marked its history. A part of the west tower has also been reconstructed due to a collapse of the south walls, replacing all the vaulted ceilings with wooden ones and inserting internal stiffening walls. The other fourth periods embrace the medieval and modern age, with some reinforcement works, an elevation of the two towers and several decorative enrichments in relation with historical events. In the fifth and sixth period the gate had not evident external transformations, while important distributive internal changes have been carried out. This happened mainly for the change of building use, from the home of the soldier devoted to goods control to the private home of the fascist hierarch Ettore Muti, until the Museum of the Walls. The last period starts with the works planned during the Jubilee, aimed at improving the gate accessibility with some conservative interventions. Today the gate is in a state of controlled conservation, still hosting the Museum of the Walls with several exhibitions. The complex distribution of the building does not appear from the outside, from which the monumentality of the work and the small traces of the evolution of the building can be observed. The interior, on the other hand, presents a very complex articulation of spaces, only partially accessible to the public.

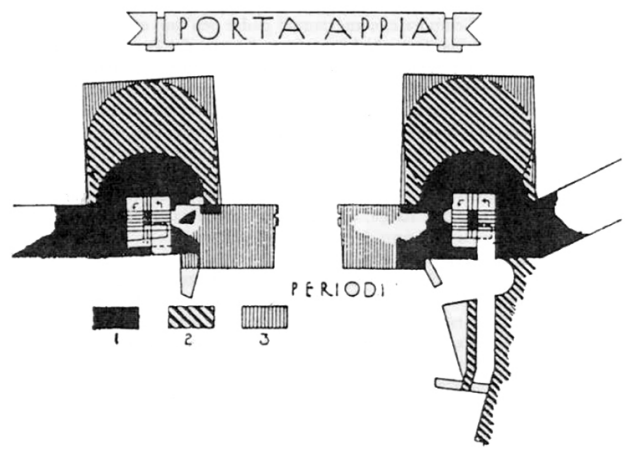

Fig. 2. Evolution schema of the exterior gate transformation (Richmond, Jacobsen, 2013). 


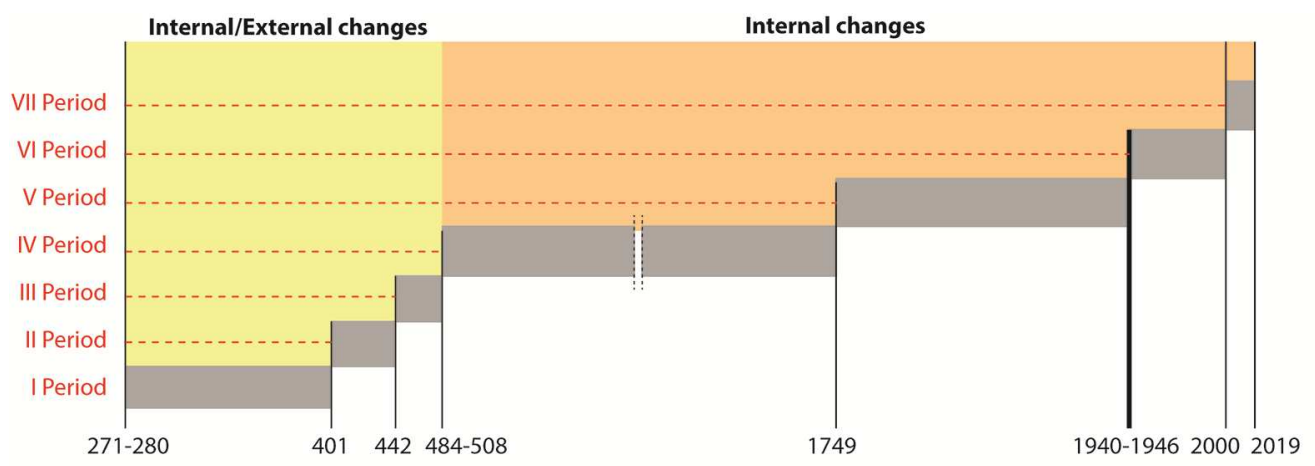

Fig. 3. Time chart summarizing the internal and external structural evolution of the gate.

\section{Methodology}

The geometric, material, structural, distributive and functional knowledge of any artefact can be obtained through an integrated survey methodology (Guidi, et al., 2010), investigating the gate at different scales (Canciani, et al., 2016). Therefore, also for this case study, a knowledge pipeline based on survey has been planned, according to the well-known codifications which must be adapted to the specific example. (Docci, Maestri, 2009; Cundari, 2012).

\subsection{Data acquisition}

The study of iconographic and bibliographic sources represents an indispensable first step in the architecture knowledge. Through this analysis, a contextualization of the palimpsest in the historical evolution of the city is possible, correlated with the main anthropic and natural events over the centuries, which have substantially contributed to define the current shape (Nibby, 1820). The case study, halfway between architectural and urban scale, led to examine on the one hand the urban gate location in the historical maps and paintings, on the other hand its architectural transformations.

Completed the sources analysis, the study turned to the state of fact survey, a hinge step to validate the historical study and preparing the interpretation phase. San Sebastiano Gate presents a complex architecture from a geometrical and distributive point of view, since the important size $(37,8 \times 12,5 \times 27 \mathrm{~m})$, the strong presence of vegetation close to the north façade (Fig. 1), the articulated internal space distribution over seven very different floors, accessible through different blocks of stairs. Such complexity rules out a topographical survey, suggesting the integrated application of active and passive techniques. Beside 3D laser scanning, photogrammetric methodology has become increasingly important in the study of complex architectures (Remondino, 2011). For the 3D active acquisition campaign, a 3D laser scanner Focus 3D X120 (Faro) was used, showing a very good portability and ease handling to detect each single interior and staircase blocks. The working internal distance has ranged between 1 to $10 \mathrm{~m}$, collecting range maps with a mean resolution of $0,5 \mathrm{~cm}$ and $1 \mathrm{~mm}$ of accuracy (Guidi, et al., 2014). Besides, an external 3D survey campaign was planned, aimed at acquiring the entire wall face and a small portion of the Aurelian walls connected to the gate, with a larger mean resolution step of 2-3 cm and an accuracy below $1 \mathrm{~cm}$. The alignment between internal and external scans was carried out using a sequence of internal-external scans produced thanks to the presence of numerous windows and many environment landmarks.

The photogrammetric project, which concerned only the external façades of the gate (Ippolito, Bartolomei, 2014), started with GCP acquisition with TCR 703 total station and GPR111 reflective prism (Leica Geosystem). At the end of the campaign, 25 points were acquired on the north façade and 27 points on the south one. The collimation activity was carried out by two distinct correlated station points (open network), positioned respectively close to the Druso Arch and 
at the intersection between Via Appia Antica and the Porta Latina avenue. Particular attention was paid in collimation activity on the north façade for the complex operating conditions, resulting from the vegetation presence, the not easy collimation of the highest points and the intense vehicular traffic. For this latter, a double collimation of each point has been planned, verifying errors due to the abnormal pavement vibrations. The photo campaign was conducted with a compact $16 \mathrm{Mpx}$ DSC-WX80 camera (Sony) mounted on a telescopic pole that reaches $11 \mathrm{~m}$ in height. The highest point of acquisition didn't allow to obtain a homogeneous geometric resolution in the whole façade, obliging to acquire additional oblique images respect to the parallel ones. A better GSD consistency would have been achieved using an RPAS (Russo, et al., 2019), but no permission to fly has been given by local offices. The photogrammetric acquisition of the south side did not encounter any problems, thanks to the good operating conditions, which allowed to plan a $60 \%$ horizontal per $80 \%$ vertical image superimposition. The only constraint has been represented by Porta Latina avenue, that forced to plan a working distance of $23 \mathrm{~m}$ with a horizontal baseline of $10 \mathrm{~m}$ and 4 $\mathrm{m}$ in vertical direction, losing some façade details (Fig. 4). Besides, the photogrammetric block on the north side showed several problems, mainly due to the presence of vegetation that leans against the wall face, obscuring some important building views. For this reason, a third photogrammetric campaign devoted to the acquisition of the connecting arch has been planned, joining the two main photogrammetric blocks and trying to solve some shadows effect.

\subsection{Data processing}

The geometric data have been carefully processed, in order to preserve architectonic characteristics useful for the interpretation analysis passage. One cleaned detailed point cloud was obtained aligning 210 range images within JRC Reconstructor (Gexcel) program. A subsampling activity of the point cloud with a step of $2 \mathrm{~cm}$ has been carried out, in order to optimize uniform data management, reserving the possibility to reuse the ultra-dense point cloud in any useful occasion (Fig. 5). Such optimized point cloud was then imported into ReCap (AutoDesk) and the drawing activity of plans, elevations and sections within AutoCAD (AutoDesk) has been started.

The images were processed within the SfM Metashape sw (Agisoft), pre-orienting the three photogrammetric blocks within the same project: south façade, north façade, arch connection.

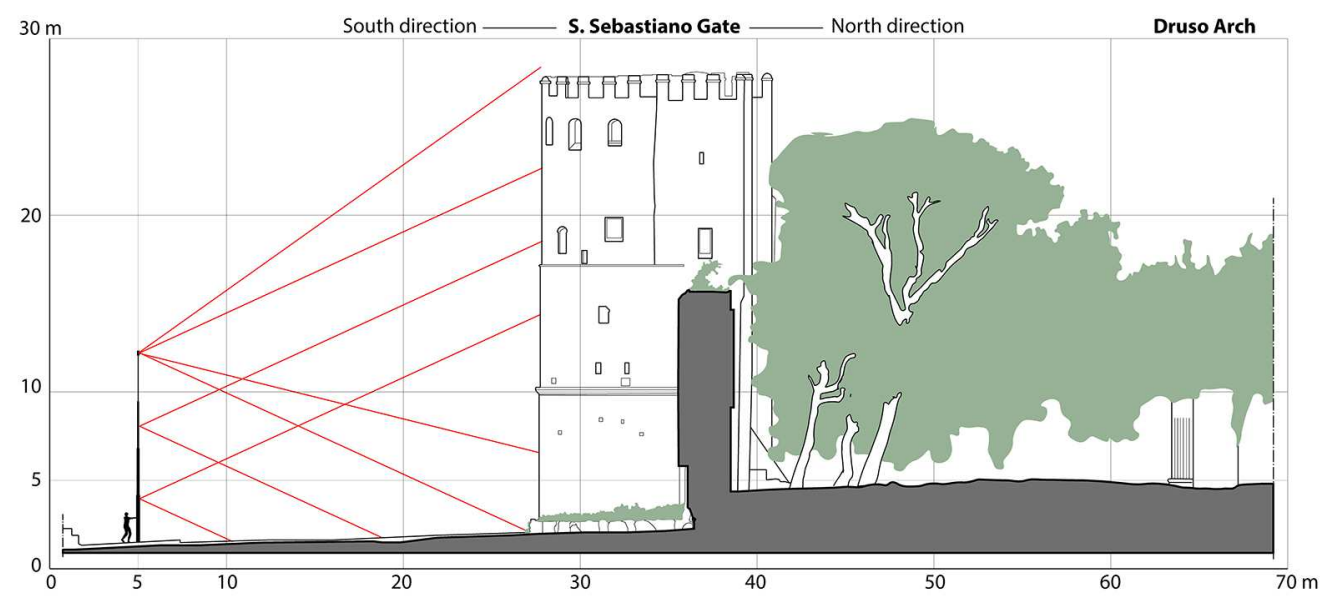

Fig. 4. Photogrammetric acquisition schema of the south façade of the gate. 


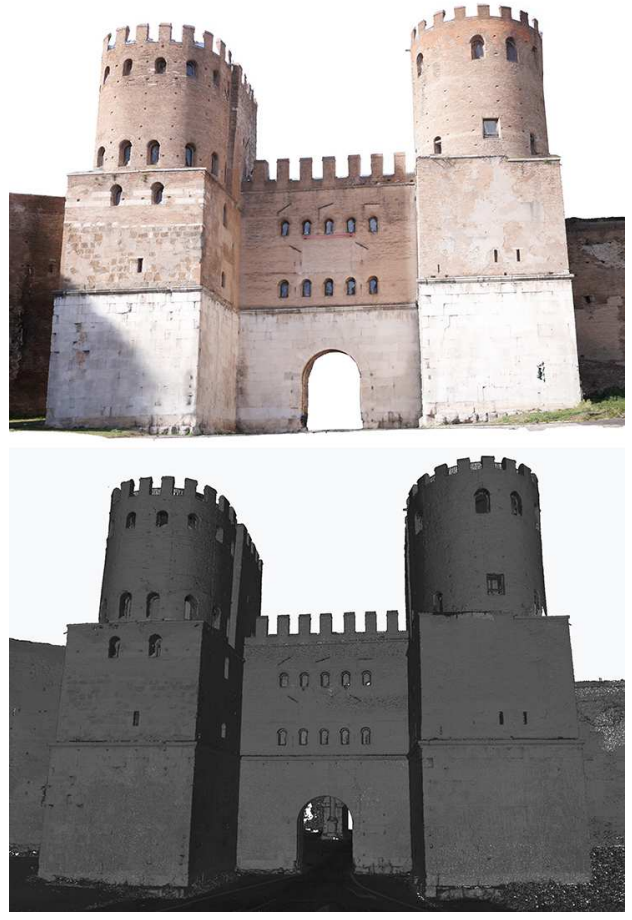

Fig. 5. Point clouds on the outside gate obtained through photogrammetry and SfM (top) and range sensor (bottom).

Than bundle adjustment has been supported with GCP, scaling and positioning the images in the same topographic reference system. Finally, the well-known SfM process of generating the dense cloud (Fig. 5), the textured numerical model and the orthophotos extraction was completed. (Luhmann, et al., 2014).

The images about the north façade presented several lacks, due to the complex external conditions, which should have been partially solved through a long masking activity. Stating this unavoidable shadowing effect, which would severely affect the data quality, images of the north façade have not been processed. For this reason, the representation activity about this part of the building refers to 3D range data, waiting to plan a better photogrammetric solution. Instead, images of the south façade are characterized by a $2,3 \mathrm{~mm} /$ pix resolution coherently distributed in the lower and medium band, while the upper part result stretched with higher GSD. The average accuracy of the final image orienta- tion has been approximately $3 \mathrm{~cm}$. The final orthoimage (Fig. 6) presents some image artefacts, mainly due to re-projection errors and the medium quality of the compact camera, an obliged solution for the telescopic pole. The integration between range data and image data has been again very useful to highlight historical fabric transformations, not visible both with range data and naked eye.

\section{Results}

The integration between active and passive sensors has allowed to collect appropriate data to draw plants, elevations and sections. The latter, very useful for the Superintendence, highlighted the internal distribution complexity of the gate, substantiated by variable vertical connections, suggesting an open problem focused on the representation of complex distribution systems using only orthogonal projections. In addition, this topic stressed the complex choose of the best horizontal sections, since the upper part of the gate presents a continuous variation in the vertical spatial distribution. Plans showed some asymmetries or deformations, mainly concentrated on the south tower, which were likely due to both structural collapses and walls reconstruction that has not considered the original curvature radius.

The geometric analysis (Fig. 6) has shown how the plans, considered as a block of two towers and the access gate, are inscribable in a rectangle of 7 per 3 modules, with a unit of $470 \mathrm{~cm}$, the same measure of the curvature radius of both towers. This module is also close to $446 \mathrm{~cm}$, corresponding to 15 Roman feet. The depth of the block between the two towers is about $470 \mathrm{~cm}$, while the relative façade is 3 modules wide, i.e. about $14,10 \mathrm{~m}$. So, a two modules composition of the external symmetrical towers and three modules one of external gate body is highlighted by the analysis. According to the sources, the coincidence between the two axes of the historic arches and the applied modules framework cannot be excluded. Over time many structural interventions, mainly attributed to Onorio, have transformed the gate shape and volumes, moving away from the original structure. The application 
of the hypothesized modules is partially confirmed also by the graphic analysis carried out on the façade. The huge rectified travertine blocks, inserted during past consolidation activity of the towers, follows the module framework in height and width with two modules of 470 $\mathrm{cm}$. The upper limit of the squared but not covered towers does not refer to the geometric framework, but that reference appears in the stringcourse placed just below the battlements of crowning, present on the central body. At the end, extending the grid to the round towers, a substantial deviation of the shape from the model assumed is shown, probably due to the continuous structural and functional changes happened over time, which have moved away from the original structure (Fig. 6).

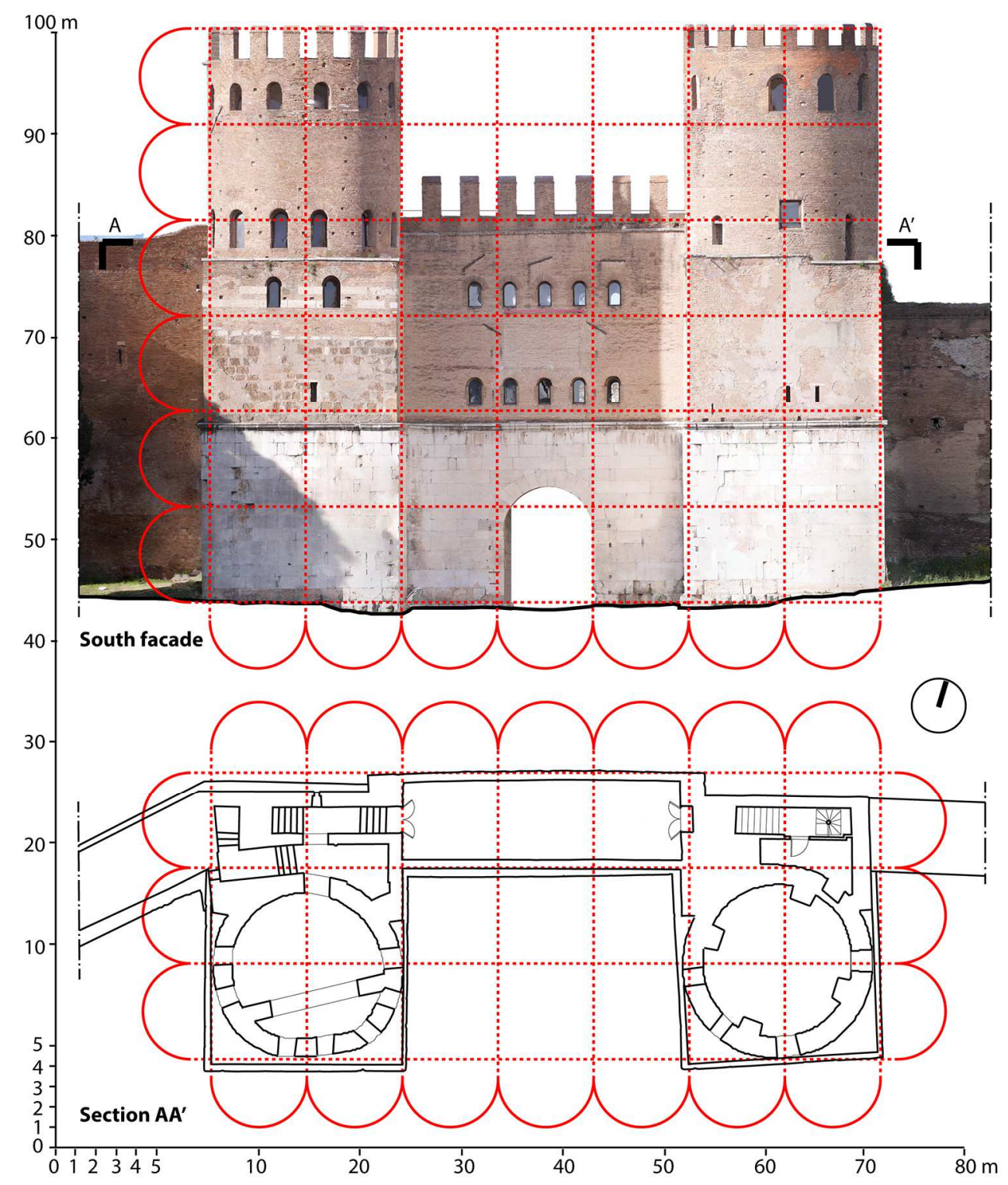

Fig. 6. Geometric analysis of the façade and the gate plan. 


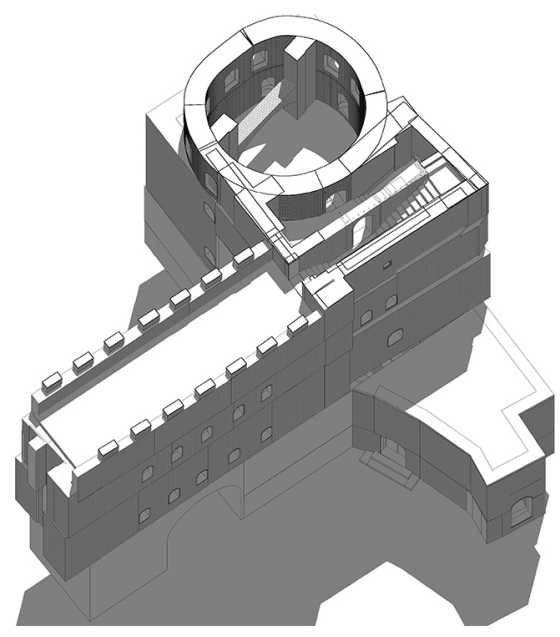

Fig. 7. Axonometric view of the BIM model of a portion of the gate (west tower and arch).

Starting from the drawings, a first BIM modelling activity related to a small portion of the gate was experimented in Revit (AutoDesk). The test involved the west tower for the presence of formally significant and complex elements (Fig. 7). The research has verified the well-known bottlenecks of this modelling approach to represent complex existing architecture (Carnevali, Lanfranchi, Russo, 2019). The presence of many irregularities and freeform surfaces in the building, from the variable walls section to the windows shape, from the complex stairs to the vaulted apparatus, have shown that BIM approach, in its undeniable potential, still presents strong limitation in complex shape representation, unless using standard 3D modelers as filter to generate complex shapes, which, however, do not possess material stratification of BIM models. Otherwise, the generation of families allows to manage singularities but with a great deal of time.

\section{Conclusions}

The experience conducted on the San Sebastiano Gate in Rome has shown once again the great potential of indirect survey methods applied to complex architectural systems, contributing to gain the knowledge already acquired with the study and analysis of the sources. The historical stratification of almost two thousand years defines a complex schedule from many points of view, so an integrated survey approach can lead to understand better the space analysis and the building evolution to the current form. The use of an active instrument with good handling characteristics and small size has been the best answer to complete the geometric survey of the entire structure, while the photogrammetric and SfM methodology has enriched the material information, helping the interpretation passage based on module frameworks. Besides, the representation of such complex artefact has presented several bottlenecks. The codified use of orthogonal reliable projections was enough to start the interpretation activity of the global system, without giving a complete and adequate representation of the complex internal space distribution. For this, the use of $3 \mathrm{D}$ visualization can represent the best solution to visualize complex realities in a dynamic way. In this specific case, the experimental application of a 3D BIM modeler has stressed this aspect, showing on the other hand its limits, mainly due to the geometrically correct representation of complex architectural artefacts.

\section{Note}

The authors shared the entire path of study and knowledge of the building, discussing the results. In the drafting of the article, paragraphs 1 and 2 were written by F.L., paragraphs 3 and 4 by M.R. while the conclusions are from L.C.

\section{Acknowledgments}

The authors would like to thank Ersilia Loreti, Director of the Museum of the Walls, for the availability shown both during the survey and in the source collection. In addition, a special thanks to Prof. Empler, responsible for the scientific cooperation agreement between Superintendence and Sapienza University concerning Via Appia Antica park. Finally, the authors would like to thank architect Eleonora Buonanni, for having experimented with the use of the BIM modelling system and the engineer Valentina Russo, for having contributed to the photogrammetric acquisition of the gate. 


\section{Bibliography}

Brizzi, B. (1995). Mura e porte di Roma antica, Colombo Ed., Roma.

Cambedda, A.; Ceccherelli, A. (1990). Le mura aureliane dalla Porta Appia al Bastione Ardeatino, Palombi Ed., Roma.

Canciani, M.; Cecili, F.; Gallo, M.; Persiani, C. (2016). "La Porta Tiburtina delle Mura Aureliane a Roma: dal rilievo 3D alla ricostruzione virtuale delle fasi storiche", in Rappresentazione materiale/immateriale, Gangemi, Roma, pp. 391-398.

Carnevali, L.; Lanfranchi, F.; Russo, M. (2019). "Built Information Modeling for the 3D Reconstruction of Modern Railway Stations", Heritage 2019, 2(3), pp. 2298-2310.

Cundari, C. (2012). Il Rilievo Architettonico. Ragioni. Fondamenti. Applicazioni, Aracne, Roma.

D’Ippolito, M.G. (2017). Le fasi costruttive di porta appia e i risarcimenti altomedievali delle mura aureliane, Tesis Doctoral, Sapieza, Università di Roma.

Docci, M.; Maestri, D. (2009). Manuale di rilevamento architettonico e urbano, Laterza Ed., Roma.

Gallavotti Cavallero, D. (1989). Rione XXI - San Saba, Palombi Ed., Roma.

Giovenale, G. (1931). "Le porte del recinto di Aureliano e Probo", in Bullettino della Commissione Archeologica Comunale di Roma, Arte della stampa edizioni, LIX, Roma.

Guidi, G.; Russo, M.; Beraldin, J-A. (2010). Acquisizione e modellazione poligonale, McGraw Hill, Milano.

Guidi, G.; Russo, M.; Angheleddu, D. (2014). "3D Survey and virtual reconstructionof archaeological sites", in Digital Applications in Archaeology and Cultural Heritage, Elsevier, Amsterdam, vol. 1, pp. 55-69.

Ippolito, A.; Bartolomei, C. (2014). "La gestione del dato di rilievo attraverso software open source: il sistema delle porte bolognesi”, Italian survey \& International experience, Gangemi, Roma, pp. 897-905.

Luhmann, T.; Robson, S.; Kyle, S.; Boehm, J. (2014). Close-Range Photogrammetry and 3D Imaging. Second edition, De Gruyter, Berlin.

Mancini, R. (2001). Le mure aureliane a Roma: atlante di un palinsesto murario, Quasar Ed., Roma.

Nibby, A. (1820). Le mura di Roma disegnate da Sir William Gell e illustrate con testo e note da A. Nibby, Vincenzo Poggioli stampatore camerale, Roma.

Remondino, F. (2011). "Rilievo e modellazione 3D di siti e architetture complesse", DisegnareCON, 4 (8), pp. 9098.

Richmond, I.A.; Jacobsen, T.C. (2013). The City Wall of Imperial Rome: An Account of Its Architectural Development from Aurelian to Narses, Westholme Publishing Ed.

Russo, M.; Carnevali, L.; Russo, V.; Savastano, D.; Taddia, Y. (2018). "Modelling and Deterioration Mapping of Façades in Historical Urban context by Close Range Ultra-Lightweight UAVs Photogrammetry", International Journal of Architectural Heritage, 13 (4), pp. 549-568.

Staccioli, R.A. (1969). L'arco di Druso e la porta San Sebastiano, Capitolium Ed., Roma, pp. 143-148.

Tomassetti, G. (1975). La campagna romana antica, medioevale e moderna, in Chiumenti, L.; Bilancia, F., eds., Leo S. Olschki Editrice, Firenze, II. 